\title{
DAS ORIGENS DA BELÉM SEISCENTISTA E SUA HERANÇA TUPINAMBÁ
}

\section{ARTIGO ORIGINAL}

PEREIRA, Carlos Simões ${ }^{1}$

ALMEIDA, Arthur da Costa ${ }^{2}$

PEREIRA, Carlos Simões. ALMEIDA, Arthur da Costa. Das origens da Belém seiscentista e sua herança Tupinambá. Revista Científica Multidisciplinar Núcleo do Conhecimento. Ano 05, Ed. 10, Vol. 03, pp. 146-160. Outubro de 2020. ISSN: 24480959, Link de acesso: https://www.nucleodoconhecimento.com.br/historia/herancatupinamba

\section{RESUMO}

Este trabalho é o resultado de uma pesquisa bibliográfica sobre as origens históricas da cidade de Belém, metrópole da Amazônia, localizada às margens da Baía de Guajará, no lado oposto à Ilha de Marajó. Baseado principalmente na obra de D'Evreux, um cronista francês que andou por estas bandas por volta de 1613, logo depois da fundação do Forte São Luís, no atual estado do Maranhão, acompanhando os invasores franceses. Antes dessa época, já havia no Marajó o Cacicado Marajoara, um agrupamento indígena dos tupinambás, desde $\circ \mathrm{V}$ século da Era Cristã. Possivelmente por conta de mudanças climáticas, ocorreu a queda do Cacicado, levando a que transferissem a sua capital Meiry para o lugar onde hoje se ergue a cidade de Belém. Com a efetiva conquista do território pelos portugueses, os tupinambás foram para outros cantos e muitos se misturaram com a população, dando

\footnotetext{
${ }^{1}$ Doutor em Engenharia Elétrica (UFPA), Mestre em Engenharia Elétrica (UFPA), Engenheiro Eletricista (UFPA).

2 Doutor em Engenharia Elétrica (UFPA), Mestre em Matemática Aplicada (UFPA), Bacharel em Matemática (UFPA).
} 
origem ao caboco paraense. Sua língua, bem como sua cultura, foram suprimidas pelos invasores europeus, principalmente depois do governo português do Marquês de Pombal, que expulsou os jesuítas da Amazônia. Vestígios dessa cultura tupinambá existem até hoje, principalmente nas comidas típicas, nos nomes de lugares, de ruas, de animais, no uso medicinal de plantas nativas, bem como na língua do dia a dia dos paraenses, tanto nas palavras como no modo de pronunciar alguns fonemas.

Palavras-chave: tupinambá, tupi de Belém, Meiry, Cacicado Marajoara.

\section{INTRODUÇÃO}

A história do Brasil durante o descobrimento e colonização, é principalmente composta por relatos que tinham como escopo o trecho do Brasil que vai do nordeste ao sul e como estes relatos foram amplamente divulgados, as coisas aqui do Norte careceram de uma maior divulgação.

Mas outros viajantes como os espanhóis e franceses, nos dão uma boa visão dos acontecimentos no norte do Brasil, como é o caso do francês Ives D'Evreux que acompanhou durante 2 anos as peripécias de Daniel de La Touche que tinha como objetivo final a conquista de nossa região para a formação da sua França Equinocial, visão essa, usada neste texto, como um adendo à nossa história muito pouco contada.

Em 1580 o capitão Português Castelo Branco, vindo da Capitania de Pernambuco, chegou à região do rio Guamá e igarapé do Piry, para implantar um posto militar de controle, a mando do Rei Dom Manoel, soberano da União Ibérica - veja que só em 1595 o padre Anchieta trazia a lume a sua Gramatica Tupi (ANCHIETA, 1595), sendo Tupi uma redução de tupinambá. A União Ibérica materializou-se, com o casamento em 1526 de Izabel, filha de Dom Manoel de Portugal com Carlos V de Espanha. A palavra Piry vem de pi 'pé' - $r$ - $y$ 'água', o junco (Rhynchospora cephalotes, que vegeta em terrenos pantanosos e Guamá vem de gua 'enseada' e ma 'oxalá', « oxalá já seja a enseada » para onde os indígenas se dirigiam remando para Mairi. 
A escolha do local se deveu ao fato da existência de um antigo e movimentado aldeamento, denominado Mairi, com a presença principalmente de índios Tupinambás e Pacajá, comandados pelo cacique Guaimiaba, cuja etimologia tupinambá é guay 'água do porto' mi 'pé' aba 'pessoa', ou pessoa com o pé na água do porto, talvez significando sua autoridade sobre as águas de Mairi. Era uma federação de povos oriundos da Cultura Marajoara, com indígenas da região ou que aqui chegavam (NEVES, 2006).

Esse posto em Mairi marcou o início da ocupação militar da União Ibérica ou Dinastia Filipina na região, para defesa luso-espanhola da entrada na Amazônia de estrangeiros que disputavam o domínio do território das drogas do sertão e a colonização do então denominado Império das Amazonas.

Mairi era um entreposto indígena com intensa movimentação de etnias em processo de migração entra a Região de Marajó e o baixo amazonas (Tupuliçu e Pauxis, mais tardes mudados para Santarém e Óbidos, a mando do português Marquês de Pombal), como mostra Frikel (1970), que aplicou técnica etno-histórica na análise do povo Caxyuana na região de Óbidos, para os quais os pajés diziam que "seu povo era composto de povos vindos de altas montanhas ao norte da li" e povos que "vinham de kampixi, no nascente, onde foi feito Bere (Belém), e perto deles moravam os Marayo", e também citavam os "ingarune", e estes últimos nos remete aos igaruana, como eram conhecidos os povos de Marajó que andavam sempre em canoas, com etimologia tupinambá igara'u'anace 'parente da canoa'.

No início de 1600 o grupo indígena waiãpi, estava fugindo de seu local de origem - a foz do Xingu -, tendo alguns se dirigindo ao norte pelo rio Jari, enquanto outros afluíam para Mairi. Em seu trabalho sobre os waiãpi do Amapá, Gallois diz que os waiãpi consideram Mairi como sua terra ancestral (GALLOIS, 1994), o que pode estar correto, pois antes de migrarem para o Amapá na fronteira com as Guyanas estiveram por aqui e testemunharam a construção de Belém, inclusive do forte do Presépio. Há também a proposição de que mair seria como os tupinambás chamavam os franceses, isso pelo fato de existir no francês a palavra maire significando prefeito, ou seja, os tupinambás deveriam saber francês. Ou algum francês assim os obrigou a falar; mas 
os próprios franceses diziam que eles os chamavam de 'papagaios amarelos' ou aiuru juba em tupinambá (PIANZOLA, 1991) além do mais a existência de Mairi é bem anterior à chegada dos franceses.

As migrações sem ou com miscigenações eram comuns entre os indígenas da Região, comportamento que se supõem, fora imposto principalmente por grande catástrofe climática em cerca de 410 d.C. (WOHLETZ, 2009) que iniciou a diáspora dos povos da Cultura Marajoara, e que em função disso, vieram a ser conhecidos como tupã'mbae ou tupinambá.

Devido às características de entreposto, o nome mairi acabou entrando no léxico tupinambá com o significado de cidade, ou urbe, de maneira geral, ou seja, mairié um aglomerado com atividades típicas de uma cidade da época, com feiras, oficinas, salga de peixes e carnes, e olarias - um entreposto de comercio.

Um grande aglomerado urbano, como mostra a Figura 1, um prato cerâmico recuperado do local denominado ponta de Pacoval no lago Arari, representação estilizada de um mapa da região do lago - Maery -, só existiu nos tempos que ficaram conhecidos como Cultura Marajoara (OBERG, 1955), (MEGGERS, 1987), (CAZAL, 1817), estabelecida no entorno ao lago que hoje se conhece como Arari, que abrigou, segundo estimativas uma população de cerca de 100 mil pessoas, que atingiu seu auge em cerca de 400 d.C. $O$ folclore marajoara diz que esse aglomerado urbano de palafitas e em terra firme se chamaria Maery, do tupinambá maen 'visão' e ryry 'tremida' (SYMOES, 2020), que era como se via de longe esse aglomerado em função da diferença de temperatura entre a agua do lago Arari e a terra, eu seja era uma miragem, e desse modo Mairi seria uma variante de Maery. 


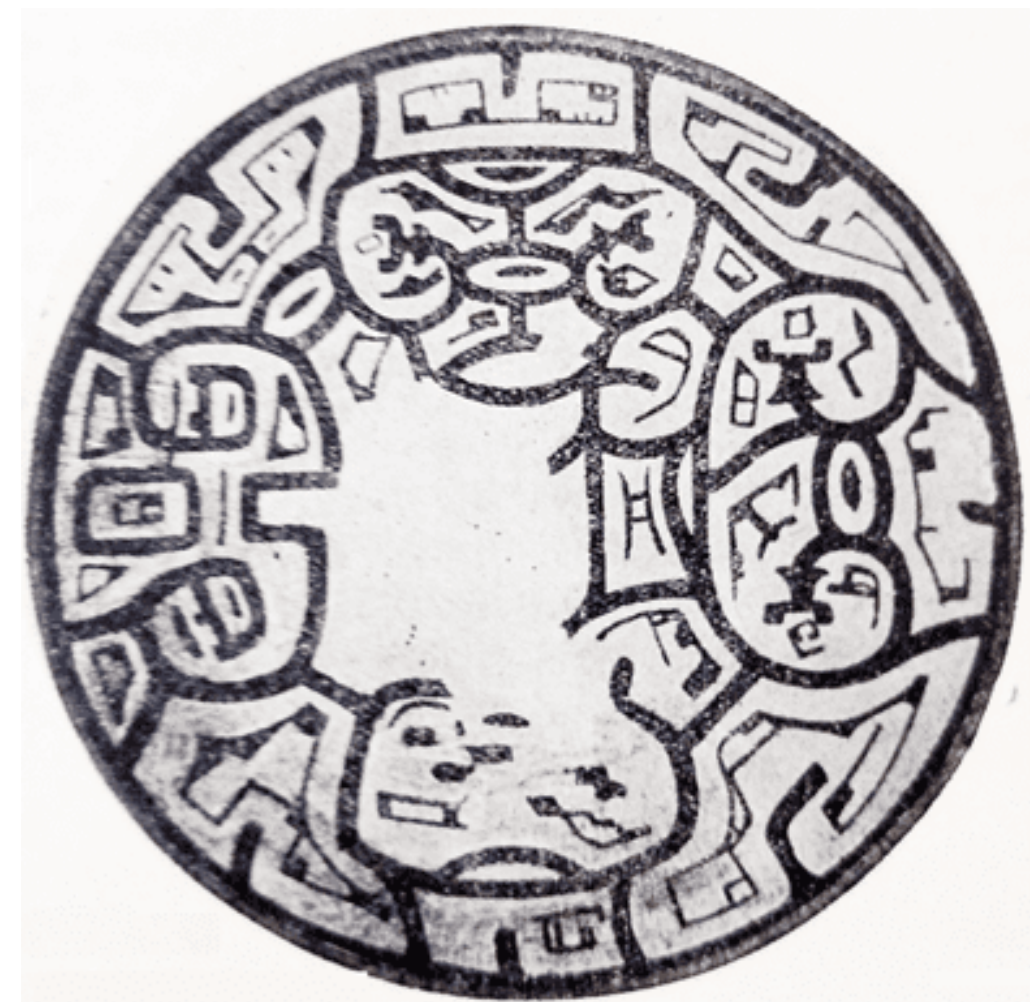

Fig 1 - Maery, cerâmica com o mapa do Lago Arari (Fonte: Museu Goeldi)

Mas a partir de 410 d.C. Maery já estava em processo de dissolução, começando a decair, como também aconteceu com outras culturas contemporâneas, como a Maia, na américa central, levando a conjectura que se deveu a um evento climático severo, existindo estudos modernos que apontam pra uma erupção vulcânica na indonésia que ejetou para a atmosfera milhões de toneladas de poeira na faixa equatorial que atingiu severamente as populações na faixa do equador, como na atual Marajó, levando à ocorrência de chuva ácida, seca e morticínio de peixes no lago Arari, que sustentava essas populações. Essa catástrofe climática certamente teve como consequência grandes migrações dos povos da cultura marajoara para o sul.

Considerando essa grande migração, a região onde está Mairi, pode ter sido uma espécie de entreposto migratório, ou seja, a função da grande metrópole do Cacicado Marajoara[3] no lago Arari foi transferida para esse local, sendo the dada o mesmo nome da capital Marajoara, um reflexo muito humano de darmos nomes de nossa região a outras plagas que visitamos, ou para as quais nos mudamos, ação muito 
exercida pelos portugueses que davam nome de cidades portuguesas àquelas que fundavam aqui, ou usurpavam dos nativos.

\section{AS INCURSÕES FRANCESAS}

O interesse dos franceses era tomar o norte do Brasil aos portugueses, cujo rio emblemático era o Marañon, rio que nasce no Peru e se estende até aqui, onde desagua no Atlântico, e por onde se procurava o 'El Dorado' - lugar cheio de ouro e pedras preciosas. Numa dessas procuras, saindo do Peru, o espanhol Orellana disse que a altura do que hoje é a cidade Juruti (no lado oposto da foz do rio Nhamundá que é obstruída por ilhas de aluvião) combateu com mulheres guerreiras e informou o seu rei quando de regresso à Espanha, que então sugeriu que o nome do rio passasse a ser chamado 'rio das amazonas' (CARVAJAL, 1542). E de tanto procurar e não achar o 'El Dorado' acabaram associando-o também às 'amazonas' a sua posse ou o seu conhecimento.

Hoje o rio, no Peru onde nasce continua sendo chamado de Marañon, quando entra no Brasil passa a ser o Solimões e depois próximo ao rio Negro, é que passa a ser Amazonas.

Nesses tempos podia-se vir da Europa para o Brasil por duas rotas: A de Colombo vinha na direção do Caribe e depois descia, passando pelo litoral da Guyanas até a ilha dos tupinambás, como fez o espanhol Pinzon, em 1498, quando da terceira viagem de Colombo à América, desgarrando-se de Colombo, desceu do Caribe pela costa das Guyanas, até a ilha que era, pelos seus cálculo, a antípoda das Molucas, as ilhas das especiarias (que Colombo queria alcançar). Essas visitas se deviam ao Tratado de Tordesilhas, que particionava terras entre Portugal e Espanha, num e noutro lado de um meridiano, que, pelos cálculos deles, passava pela atual ilha Marajó, e seu antemeridiano, passava no arquipélago das Molucas. Nessa viagem Pinzon até batizou de Mar Dulce o tal rio que mais tarde viria a ser 'das amazonas'.

Depois tinha a rota de Cabral margeando a costa da África e depois desviando para a costa do Brasil, podendo ir para o sul ou para o norte. 
Em 1604 Daniel de La Touche e Jean Mocquet, guarda das curiosidades de Henrique IV e Luiz XIII, reis franceses - o velho e o novo - vieram secretamente à região avaliando as possibilidades francesas. Observaram uma área nas Guyanas e na nossa região esperavam encontrar as chamadas amazonas em uma grande ilha no rio Marañon; esperavam encontrar o povoado Mairi que comercializava com pedrasverdes, esmeraldas, muirakitãs e muito ouro, além de arrebanhar nativos para serviços gerais e tropas de exército.

De volta à França e com essas informações La Touche convenceu Luiz e Henrique (e quando partiu este já havia morrido), a financiar uma incursão ao norte do Brasil, pois lá existia todo o necessário pra sua França Equinocial - território, recursos minerais, drogas do sertão, mão de obra e pelotões para seus exércitos.

\section{A EXPEDIÇÃO FRANCESA DE LA RAVARDIERE}

Saíram da cidade Saint-Malo, no norte da França e logo depois de Portugal, nessa época o tempo era de calmarias, pois uma anomalia meteorológica, a zona de convergência intertropical, nessa época mais ao norte, bagunçava os ventos a partir desse ponto. Os franceses de Daniel de La Touche, impossibilitados de seguir pela rota de Colombo, então pegaram a rota de Cabral, margeando a África e quando no litoral brasileiro, vindo de nordeste, acharam que aquela baia larga e a ilha eram o rio Marañon e a ilha dos tupinambás (de Pinzon) e 'das amazonas' no geral, e aí desembarcaram e construíram um forte de madeira que deram o nome de Saint Louís em homenagem a seu rei. Esse engano deu origem ao nome do estado: Maranhão e São Luís, sua capital. 


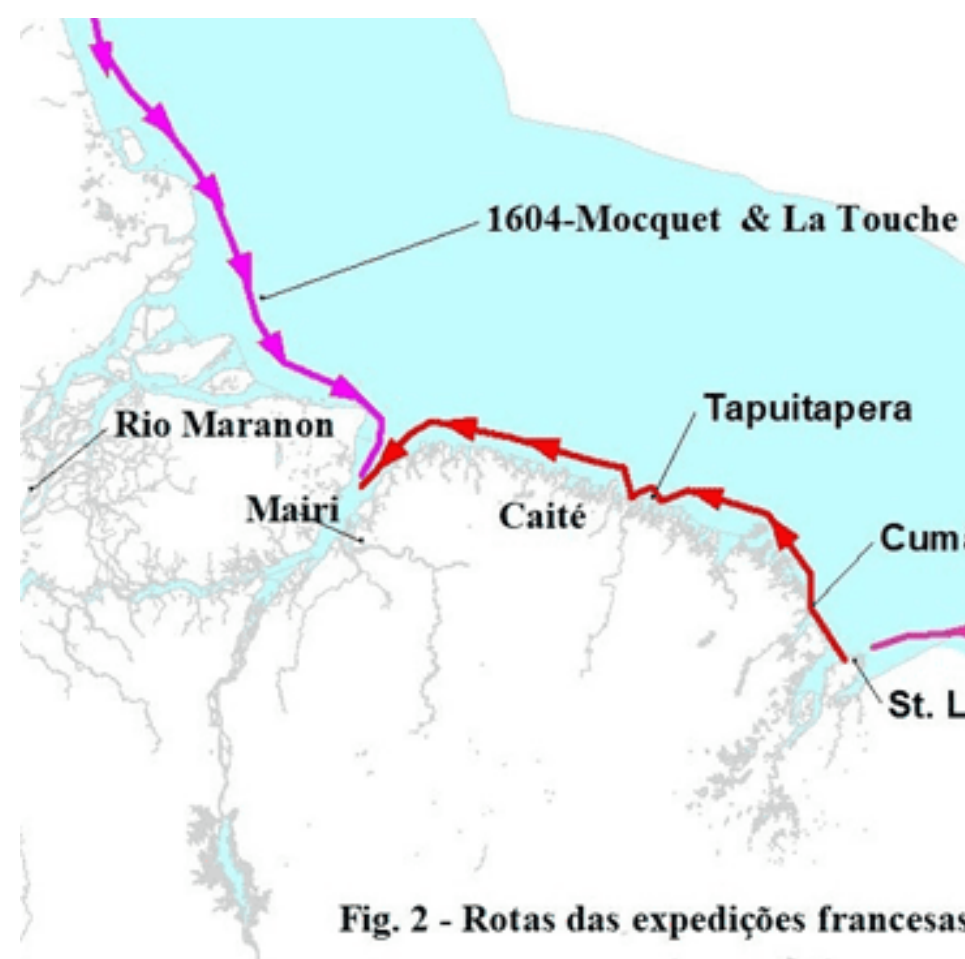

Cumã

St. Louis

O padre Ives D'Evreux (D'EVREUX, 2018), era o escriba, e como ele anotava no início, chamando para si a condição de escriba, observando que havia outro padre na expedição, pois ele ficou com os franceses desde o início até o fim da aventura:

... não repetirei aqui coisas já escritas pelo padre Claude d'Abbeville na sua 'História', e somente acrescentarei o que mais do que ele soube por experiência, pois eu estive em Marañon dois anos completos e ele apenas quatro meses. (D`EVREUX, 2018)

Além de conquistar as almas dos nativos, também indagava dos mesmos, informações sobre os seus reais objetivos (amazonas, ouro, Mairi e territórios para a França Equinocial, e registrava tudo).

Era fins de 1612, e os franceses se estabeleceram no que pensavam ser o rio Marañon e para sua defesa começaram a construir um forte, para assegurar a tomada do novo território. Dessa construção sabemos pela pena de Ives D'Evreux, um religioso capuchinho, que:

Da construção do Forte de São Luiz, e do interesse dos selvagens em carregar terra, chegado o tempo próprio de trabalhar nas fortificações da praça designada à defesa dos franceses, fincada a madeira segundo o 
plano dado para servir de cercadura ao Forte, e de sustentar as terras, mandou-se então avisar por todas as aldeias da ilha e da província de Tapuytapera, que viessem índios uns após outros conduzir a terra tirada dos fossos para os terraços das cortinas, esporões e plataformas, depois cobertas por grandes e grossas Apparituries, «mangues » arvores duras como ferro e incorruptíveis; de forma que seria contra ela quase inútil o tiro do canhão, e mui difícil a escalada: assim se disse e assim se fez : de todas as aldeias pouco a pouco vinham os selvagens com suas mulheres e filhos, trazendo viveres para o tempo, que calculavam demorar-se no trabalho, e sempre debaixo das ordens dos seus Principais, costume que geralmente observam, trazendo-os sempre na frente da Companhia, fazendo-lhes a natureza conhecer, que o exemplo dos superiores anima infinitamente os inferiores. (D'EVREUX, 2018)

Ives D'Evreux sabia que o objetivo daquela expedição estava mais para a frente e tratou de obter informações dos nativos que por ali apareciam, atraídos pela chegada dos conquistadores, e assim procurava reunir conhecimentos, inquirindo incansavelmente os indígenas. Havia a preocupação de saber como os nativos guerreavam, pois sabiam que naquela aventura a guerra seria inevitável.

Assim Ives D'Evreux escrevia:

Indaguei e procurei saber muito o modo como se preparavam para a guerra, não me contentando só com as informações. Em primeiro lugar as mulheres e as suas filhas preparam a farinha de munição, e em abundancia, por saberem, naturalmente, que um soldado bem nutrido valle por dois, que a fome é a coisa mais perigosa n'um exército, por transformar os mais valentes em covardes, e fracos, os quais em vez de atacarem o inimigo, buscam meios de viver. É diferente da usual esta farinha de munição, por ser mais bem cozida, e misturada com carimã para durar mais tempo, embora menos saborosa, porém mais sã e fresca. Assim preparados bebem publicamente o vinho de 'muay', e dizem adeus aos que ficam. (D'EVREUX, 2018)

O povoado Mairi, na área onde se construiu Belém, estava também entre os objetivos franceses e, portanto, consta no relatório do padre Ives D'Evreux que fala dele, dizendo que os franceses os chamam:

Pedras-verdes, por causa de uma montanha, não muito longe de sua antiga habitação, onde se acham mui belas e preciosas pedras Verdes, dotadas de muitas propriedades, especialmente contra doenças do baço, e frouxos de sangue, e também me disseram haver ali esmeraldas muito finas: ali iam os selvagens buscar estas pedras verdes tanto para 
colocá-las em seus lábios, como para negócio com as nações vizinhas. (D'EVREUX, 2018)

Esse tipo de pedra preciosa tem ocorrência no interflúvio entre o rio Gurupi e o rio Piriá, que a época era habitada por vários grupos indígenas e que de lá através da região do que hoje se conhece como Ourem, se comunicavam com Mairi efetuando trocas. Até os tempos atuais ficou a terra indígena Alto rio Guamá, que se inicia justamente na região das atuais cidades Ourem e Capitão Poço, e daí atravessa o rio Guamá e o Gurupi entrando no atual Maranhão (MAGALHÃES, 1935)

Outro tipo de comercio existente em Mairi e que usava mão de obra indígena, eram as chamadas 'drogas do sertão' como eram denominados entre outros, o cacau, a castanha-do-pará, o guaraná, o pau-cravo e o urucum. As "drogas" eram produtos nativos do Brasil, que não existiam na Europa e, por isso, atraíam o interesse dos europeus que as consideravam como novas especiarias.

Também as pedras-verdes nos remetem aos amuletos conhecidos como muirakitã, que seriam produzidos pelas amazonas.

Naqueles tempos aventureiros e viajantes do mundo inteiro demonstravam intensa curiosidade e cobiça em saber se o mito das mulheres guerreiras ou Amazonas, como Ihes denominava os Espanhóis era verdadeiro e se tinham mesmo grandes reservas de ouro e pedras preciosas, os franceses não eram exceção à regra, e o padre Ives não perdia tempo e registra em seu diário:

... fui visitado por um grande Principal, que morava muito acima n'este rio. Depois dos seus cumprimentos, que descreverei mais adiante, me disse morar nas últimas terras dos Tupinainbá, e que só em duas, luas podia voltar do rio Marañon a sua aldeia, e então Ihe respondi admirando-me do trabalho que tomou vindo de tão longe". Replicou-me « fui ao Pará ver meus parentes, quando foram os franceses, guerrear nossos inimigos, e ouvindo falar de vós e dos outros Padres, quis velos pessoalmente para dar notícias certas aos meus companheiros ». (D’EVREUX, 2018)

D'Evreux se dava conta que era grande o intercâmbio de indígenas vindos da Amazônia para o nordeste brasileiro e ele aproveitava as informações anotando-as 
detalhadamente. Continuando as inquisições ao nativo Ives levantou o assunto das mulheres guerreiras:

Por intermédio do meu intérprete lhe perguntei se sua residência era muito longe da das Amazonas, e ele respondeu-me «uma lua», isto é, um mês para ir, apliquei-lhe, se tinha estado, entre elas, e se às tinha visto. (D'EVREUX, 2018)

Pelo interprete o indígena respondeu: "que nem uma coisa nem outra », pois nas canoas de guerra, onde andou, se desviou da ilha onde elas residiam, e acentuou que:

«Esta palavra Amazonas llhes foi imposta pelos portugueses e franceses pela semelhança que elas tinham com as antigas Amazonas, por causa de sua separação dos homens; porém não cortam a mama direita, e nem imitam a coragem d'essas afamadas guerreiras, mas vivem como as outras mulheres selvagens, ágeis e destras no manejo do arco, e nuas se defendem dos seus inimigos, como podem » . (D'EVREUX, 2018)

Tem sido reportado por vários cronistas da época qual seria a origem das amazonas ou icamiaba, com os nossos nativos realmente as chamavam - $i$ 'pequeno' cama 'peito' iaba 'que se diz' -, que diziam, foram encontradas em vários locais, inclusive na ilha que hoje chamamos Marajó.

Um provável motivo, se é que elas realmente estavam por aqui, pode se dever ao êxodo que se seguiu à queda da Cultura Marajoara e seu Cacicado, pois os homens sempre seguiam na frente, até abandonando os mais fracos, e possivelmente, em função disso um grupo de mulheres teve que enfrentar esse desafio e depois de vencê-lo não aceitaram mais a presença dos homens, a não ser em ocasiões especiais pra garantir a existência do grupo.

As amazonas podem ser um simples mito, mas tiveram uma influência real nesses aventureiros, pois até La Ravadier as tinha como um de seus objetivos, quando decidiu invadir o norte do Brasil. 
Depois da consolidação da cabeça de ponte dos franceses no território português do Brasil, construindo um forte e celebrando aliança com grupos indígenas os franceses seguiram em frente.

O padre D'Evreux descreve a partida da expedição francesa em busca das amazonas, comandada por Daniel de La Touche, Senhor de La Ravardiere:

No dia 8 de julho de 1613 do porto de Santa Maria do Marañon, partiu o Sr. Ravardiere ao som de muitos tiros de artilharia e mosquetaria, com que o saudou o forte de S. Luiz segundo é costume entre os militares. Levou em sua companhia 40 bons soldados, e 10 marinheiros, e por cautela, também, 20 dos principais selvagens tanto da llha do Maranhão e de Tapouitapera, como de Cumā. (D’EVREUX, 2018)

A primeira parada, saindo da ilha do forte, era Cumã - uma localidade e perigosa baía, a oeste da ilha e forte Saint Louis -, para onde rumou La Ravardiere e lá o aguardava mais reforços indígenas e viveres para a viagem, que segundo Ives, onde o esperava muitas canoas de índios, e, provendo-se de farinha seguiu para Caeté onde haviam 20 aldeias de Tupinambás, e aí se demorando mais de um mês, tempo que usou para reforçar a tripulação de suas embarcações com mais 60 escravos que lhe deram.

Caeté, era como os indígenas chamavam a região do rio de mesmo nome, que vem de caa 'mato' e ete verdadeira': eles comparavam assim em contraste à região de savanas no Marajó de onde tinham vindo.

Num ponto do rio Caeté, havia um aldeamento tupinambá que os portugueses aproveitaram e trocaram o nome Caeté, como era chamado, para Bragança como passou a se chamar a cidade que ali surgia, era a estratégia portuguesa de sufocar nossa ancestralidade, e deu certo, pois hoje ninguém cogita voltar aos nomes indígenas antigos.

O rio Caeté fazia parte de uma importante via indígena, muito usada em seus deslocamentos, pois nascia próximo à atual cidade de Ourem, no rio Guamá, que funcionava como ponto de conexão para Mairi, e daí, por uma extensão de $108 \mathrm{~km}$ banha a cidade atual de Bragança, as vilas de Bacuriteua e Caratateua, e deságua na baía de Caeté, no oceano Atlântico, e D'Evreux anotou em seu diário: 
Nu dia 17 de agosto partiu de Caeté com muitos, habitantes, d'esse país e dirigiu-se para a aldeia chamada Meron, onde em grandes canoas embarcou, tanto os selvagens como os franceses e seguiu para a embocadura do rio Pará; em viagem morreu afogado um francês por ter naufragado, a canoa, em que, ele ia, porem salvaram-se seus companheiros trepados no dorso da mesma".

"O rio Pará desde a sua embocadura para cima é muita povoado de Tupiyambás; chegando à última, aldeia, situada, á 60 léguas da sua embocadura, todos os principais d'esses lugares the pediram com instancia, que fosse guerrear os Camarapins, os quais são muito ferozes, não querem paz, e por isso não poupam seus inimigos, pois quando os captivam, matam-nos e comem-nos. Poucos dias antes tinham matado, três, filhinhos dum dos principais dos Tupinambás d'aquelas regiões, e guardaram os ossos d'eles para mostrar aos pais afins de causar-Ihes vontade de duelar com eles. Este exército de franceses e de Tupinarbás, em número de 1200, saiu do Pará e, entrou no rio dos Pacajares. (D'EVREUX, 2018)

Essa descrição de D'Evreux já dá uma visão da distribuição dos tupinambás na região, principalmente da foz do rio Gurupi até o rio Pacajá, onde recebe o rio Anapu e desaguando na baia de Portel, e cujos indígenas também andavam por Mairi. Esse trajeto inclui o em torno da llha de Marajó, de onde se originaram, inclusive herdando o nome da língua geral (tupan'mbae), falada durante os tempos da Cultura Marajoara, que lentamente desapareceu, a partir de 410 d.C. sucumbida por uma catástrofe climática.

Ives D'Evreux registra que era voz geral e comum entre os selvagens, que há Amazonas, e que habitam n'uma ilha muito grande, cercada pelo grande rio do Marañon ou das Amazonas, que desemboca no mar por um espaço de 50 léguas de largura: que essas Amazonas foram antigamente mulheres e filhas dos tupinambás, que se retiraram da companhia e do domínio deles.

Os franceses passaram por Mairi, na ocasião o posto de controle português estava deserto, negociaram com os índios de Mairi e seguiram em frente subindo o rio Tocantins; em Cametá fundaram um posto colonial, região assim chamada, pois seus habitantes construíam casas em jiraus, ou palafitas acima dos rios e da floresta, que periodicamente inundava - como até os dias de hoje, os ribeirinhos da região fazem -, sendo Cametá oriundo de caa 'mato' e muta 'girau elevado'. D'Evreux registra as 
habitações dos nativos como: "... os quais moram em ilhas que são casas feitas em pontes assentadas sobre árvores que crescem nas águas." (D’EVREUX, 2018)

La Ravardiere seguiu até o bico do Papagaio, a junção dos rios Araguaia e Tocantins onde está hoje Marabá, que deve o nome aos entreveros com os franceses, cuja origem vem do tupinambá maram 'guerra' e aba 'gente', significando as gentes das guerras, ou aqueles que nasceram nessa época; significando ainda filhos de francês com índio.

De La Touche só retornou quando recebeu informação que os portugueses estavam para atacar seu forte em Saint Louis, como registrava Ives D'Evreux em seu diário:

Quando menos pensávamos, achando-se a llha sem índios e sem franceses, por terem aqueles ido viajar pelo Amazonas e ao Mairy, (Mairi), fomos incomodados com mil notícias, ora de selvagens residentes perto do mar, ora de franceses moradores do forte, que diziam ter ouvido tiros de peça para o lado da costa. (D'EVREUX, 2018)

Com a chegada de uma barca portuguesa, conta Ives D'Evreux, que o Sr. de Pezieux escreveu ao Sr. de La Ravardiere e expediu uma canoa para tal fim, descrevendo o estado em que nós achávamos e prestes a sermos sitiados em breve tempo. Esta interrupção da viagem do Amazonas causou muito mal a Colónia, porque se teria colhido muitos géneros pelas margens dos rios, muito mais povoados de selvagens de diversas nações do que a llha na qual estavam.

\section{A FUNDAÇÃO OFICIAL DE BELÉM}

Após a expulsão dos franceses do Forte São Luís, Gaspar de Souza, governadorgeral do Brasil, enviou em 1615, o capitão Português Castelo Branco (que já conhecia a região) fundando na foz do igarapé do Piry, um fortim de madeira chamado Forte do Presépio, posteriormente, abrigando uma capela denominada Nossa Senhora da Graça, dando origem ao povoado denominado Feliz Lusitânia, consagrada a padroeira Nossa Senhora de Belém, e em 1616 com a construção do Forte do Presépio em substituição ao fortim de madeira, ocorreu oficialmente a fundação de Belém. 
Em 1621, para assegurar a posse do território o Rei Filipe II de Portugal transformou a Conquista do Pará em Capitania do Grão-Pará e também criou o Estado do Maranhão com sede em São Luiz, formado pelas: Capitania do Grão-Pará, Capitania do Maranhão e Capitania do Ceará - renomeado em 1654 para Estado do Maranhão e Grão-Pará -, e devido aumento na importância econômica de Belém, em 1751 foi mudado para Estado do Grão-Pará e Maranhão, que só foi dividido em 1772, estabelecendo o limite do Estado do Maranhão até o rio Turiaçu, muito mais tarde, após a derrota da Revolta da Cabanagem em 1836, o limite com o Maranhão passou ao rio Gurupi.

Os Holandeses que recentemente haviam se tornado independentes, libertando-se da Espanha em 1581, andavam tipo os vikings, procurando tomar alguma coisa espanhola e se estabeleceram em frente ilha Grande de Gurupá já na foz do Amazonas, construindo um forte que denominaram Mariocay, estavam interessados em cacau, baunilha, e vingar-se da Espanha.

Em 1623 uma expedição colonial comandada por Pedro Teixeira, mas o grosso da tropa era de tapuios paraenses, saiu de Belém e lutou contra os neerlandeses tomando e destruindo o forte e fundando a cidade de Gurupá, nome adaptado do tupinambá guira ypaba 'garça da lagoa'.

Em 1625, na área do igarapé do Piry (no atual Mercado Ver-o-Peso), os portugueses instalaram o posto fiscal comercial "Casa de Haver o Peso" ou "Lugar de Ver o Peso", para controle do peso e, arrecadação de tributos dos gêneros trazidos para a sede da Capitania do Grão-Pará.

Em 1637, partiu de Belém uma expedição comandada por Pedro Teixeira, com 45 canoas, setenta soldados e mil e duzentos flecheiros e remadores indígenas subindo o curso do rio Amazonas, buscando confirmar a comunicação entre o oceano Atlântico e o Peru, rota percorrida no século anterior por Francisco de Orellana, sendo a viagem registrada pelo jesuíta Cristóbal de Acuña em obra editada em 1641. Acuña também pesquisou sobre as amazonas ou icamiabas. Durante dois anos, a expedição subiu o rio Amazonas, chegando até Quito, no Equador. 
Após a viagem de Pedro Teixeira, os jesuítas estabeleceram missões na região e passaram também a coletar drogas do sertão, usando indígenas. Tempos depois, a coleta passou a ser feita também por colonos, gerando conflitos constantes com os jesuítas, provocados quase sempre pela questão indígena.

A Pedro Teixeira foi creditada a descoberta do caminho que ia de Mairi para Caeté, criado pelos índios Tupinambás, que passou a ser conhecido pelo seu nome. Este caminho, em 1884 foi transformada na Estrada de Ferro de Bragança, e que posteriormente foi nomeada avenida Tito Franco, e atualmente chamamos de Almirante Barroso ao seu início. Nos tempos de nossas avós esse caminho ficou conhecido como 'estrada do Maranhão' que alimentou um fluxo de migrantes que vinham em busca de seus 'El Dorados'.

O jesuíta, padre Luís Figueira, que escreveu uma gramática tupinamba/tupi durante sua passagem pelo Maranhão, e quando vinha para Belém em 1645, para testar em campo seu tupinambá, naufragou e foi devorado pelos temidos índios aruã, que também falavam tupinambá, no litoral do Marajó, cuja etimologia vem de aru 'que opõe obstáculo ã 'coisa'.

A maciça presença do tupinamba na nossa Belém de hoje, deixou algumas estórias pitorescas, como o nome como Tenone, significando 'mais adiante', bairro em Belém com cerca de 34.000 pessoas, próximo à Vila de Icoaraci, junto aos rios Anani e Iriri: "A origem do nome Tenone é curiosa, e se deve ao fato de as pessoas que vinham a pé de Belém para Icoaraci $(16 \mathrm{~km})$, por um caminho paralelo ao trilho do ramal Icoaraci, da ferrovia Belém-Bragança, sempre encontravam pessoas de um grupo de tapuyas que moravam nessa região, e aí perguntavam - Icoaraci ainda está longe? e os tapuyas, respondiam 'tenoné!' apontando para diante."- (SYMOES, 2018). Poucos sabiam que aqueles tapuyas estavam dizendo em tupinambá que Icoaraci era mais adiante, mais para a frente. 


\section{CONCLUSÕES}

Da debacle do Cacicado Marajoara, por conta de uma mudança climática severa, sua capital Meiry, acaba sendo deslocada para a região do rio Guamá, com o nome Mairi, onde no século XVII (anos 1600) influenciou a criação da cidade de Santa Maria de Belém, ou simplesmente Belém, que vivenciou eventos marcantes como a visita dos franceses em 1604 e 1613, que queriam tomar o Norte do Brasil aos portugueses e aqui fundar sua França Equinocial; a expulsão dos Holandeses da foz do Amazonas; e Vivenciou o naufrágio do padre jesuíta Figueira, que escrevera uma gramatica para a língua tupinambá, que já havia a se denominar tupi.

Hoje, apesar da sistemática tática de mudar os nomes nativos dos lugares, por nomes portugueses, ainda podemos observar a grande penetração do tupinambá nos topônimos da região de Belém, uma prova da ancestralidade desses tempos antigos, numa miríade de nomes como os das ruas dos: Jurunas, Timbiras, Caripunas, Tupinambás, Mundurucus, Tamoios e Apinages.

Una, significando 'preto', bairro limítrofe da cidade de Belém com o município de Ananindeua, com 6.724 moradores, sendo parte da Bacia do igarapé Una - que levava esse nome pela cor de suas águas, limitada pela estrada do Una.

Utinga, formada por una \& tinga 'dois igarapés, um de água preta e o outro branca', que represados formaram um lago no parque estadual no município Belém, com área de $24 \mathrm{~km} 2$, suportando, além de base para pesquisa ambiental, atividades recreativas de canoagem, trilhas, ciclismo, corridas e passeios.

Maracangalha formado de mara 'mancha' acanga 'cabeça' ayra 'pequenino', nome de um pequeno macaco com uma mancha na cabeça que vive nas matas em redor do aeroporto Val-de-Cans em Belém, sendo essas matas conhecidas como Maracangalha. 
Aracyg de ara \& cyg significando 'mãe do dia, a aurora'; rio onde se instalou um engenho de açúcar, que originou o atual município Santa Barbara do Pará, na região metropolitana de Belém.

Arapari significando 'dia de pesqueiro', porto ao sul de Belém, na baía de Guajará com serviços de balsa e passageiros para Belém, na ilha Arapari, no município Barcarena.

Aurá significando 'falsa pintura', igarapé que nasce no município Ananindeua e serve de limite entre este e o de Belém, desaguando no rio Guamá na divisa entre os dois municípios.

Caratateua significando 'muitas batatas', uma das muitas ilhas de Belém, e um de seus oito distritos, o Distrito Administrativo de Outeiro.

Combu de koen \& mbure 'trombeta do amanhecer', ilha em Belém, com matas de açaí nativas e grandes revoadas barulhentas de pássaros ao amanhecer.

Icoaraci significando 'águas ensolaradas', um dos oito distritos em que se divide o município Belém, localiza-se próximo a ilha de Caratateua, com acesso por barco no porto da $7 \underline{a}$ rua ou em outro ponto de Icoaraci onde fica a ponte, também é possível em Icoaraci, pegar balsas diárias para Ilha do Marajó e barcos para ilha de Cotijuba.

Trambioca de tarambice \& oca 'casa do inimigo', ilha no município Barcarena, a 17 $\mathrm{km}$ oeste de Belém, na baía do Marajó. A ilha é cercada por praias, com destaque para as de Sirituba, Cuipiranga, Guajarina, do Sol e Paraíso.

Cotijuba de coty \& juba 'armadilha dourada', ilha na baía de Guajará em Belém onde existem falésias de barro amarelo que podem despencar nas pedras abaixo, e que tem como mais procurada praia a Vai-quem-quer.

No século XVIII, uma contribuição significativa para o conhecimento da língua tupinambá foi o vocabulário e gramática de 1771 que alguns estudiosos alcunharam como o "Tupi de Belém", ou como o mesmo se autodenomina "Diccionario da língua geral do Brasil que se falla em todas as villas, lugares e aldeas deste vastissimo 
Estado, 1771, Cidade do Pará" de autoria anônima, foi manuscrito em Belém com cerca de 7.600 verbetes, que em verdade começou a ser escrito em 1750, era um levantamento da fala de povos já aculturados da época, na região do Marajó e Belém, o que mostra a penetração da língua tupinambá no falar do povo e dos jesuítas. Esse documento léxico também é uma evidência da grande penetração do uso do tupinambá na região, só possível pelo uso da língua já em remotas épocas.

O objetivo do Tupi de Belém era alfabetizar os nativos na língua comum da região, o que já era de fato, e que depois da proibição pombalina, ocorrida em 1758, continuou a ser desenvolvido na clandestinidade.

\section{REFERÊNCIAS}

ANCHIETA, Jose de. Arte de Grammatica da Lingoa mais vsada na costa do Brasil, Companhia de IESV, Lisboa, 1595.

CARVAJAL, Gaspar de Relación del nuevo descubrimiento del famoso río Grande que descubrió por muy gran ventura el capitán Francisco de Orellana, Crônicas da Viagem, 1542.

CAZAL, Manoel Ayres, Corographia Brasilica, R.J. Eduardo\&Henrique Laermmert, 1817.

D'EVREUX, Ives, Voyage dans le nord du Brésil 1613-1614, Wentworth Press, Paris, 2018.

FIGUEIRA, Frei Luís, Arte da Língua geral Brasiliana, officina patriarcal, Lisboa, 1620 .

FRIKEL, Protasio, Os Kaxuyana - Notas Etno-Historicas, Boletim do Museu Paraense Emilio Goeldi, Belém, 1970.

GALLOIS, Dominique Tilkin, Mairi revisitada, NHII/USP/ FAPESP, São Paulo, 1994.

MAGALHÃES, Couto de. O selvagem, Cia Editora Nacional, RJ, 1935. 
MEGGERS, B. J. The early history of man in Amazonia. T.C. \& Prance, G.T. (org), 1987.

NEVES, Eduardo Goes, Arqueologia da Amazônia, Jorge Zahar, Rio de Janeiro, 2006.

OBERG, K. Types of Social Structure among the Lowland Tribes of South and Central America. American Anthropologist, 57, 1955.

PIANZOLA, Maurice, Des Français à la conquête du Brésil (XVII siècle): Les perroquets jaunes, L'Harmattan, Paris, 1991.

SYMOES, Carlos. As Desaventuras do Grão-Parah. Amazon.com, 2018.

SYMOES, Carlos, O Tupi de Belém, Dicionário Tupinambá-português, Amazon.com, 2020.

WOHLETZ, Ken, Were the Dark Ages Triggered by Volcano-Related Climate Change? Los Alamos National Laboratory, 1995.

\section{APÊNDICE - REFERÊNCIA DE NOTA DE RODAPÉ}

3. Um cacicado é um império, ou uma grande região comandada por um rei, como o império Maia que deixou estruturas em pedra. Como no Marajó não tinha pedras, o nome é cacicado.

Enviado: Maio, 2020.

Aprovado: Outubro, 2020. 